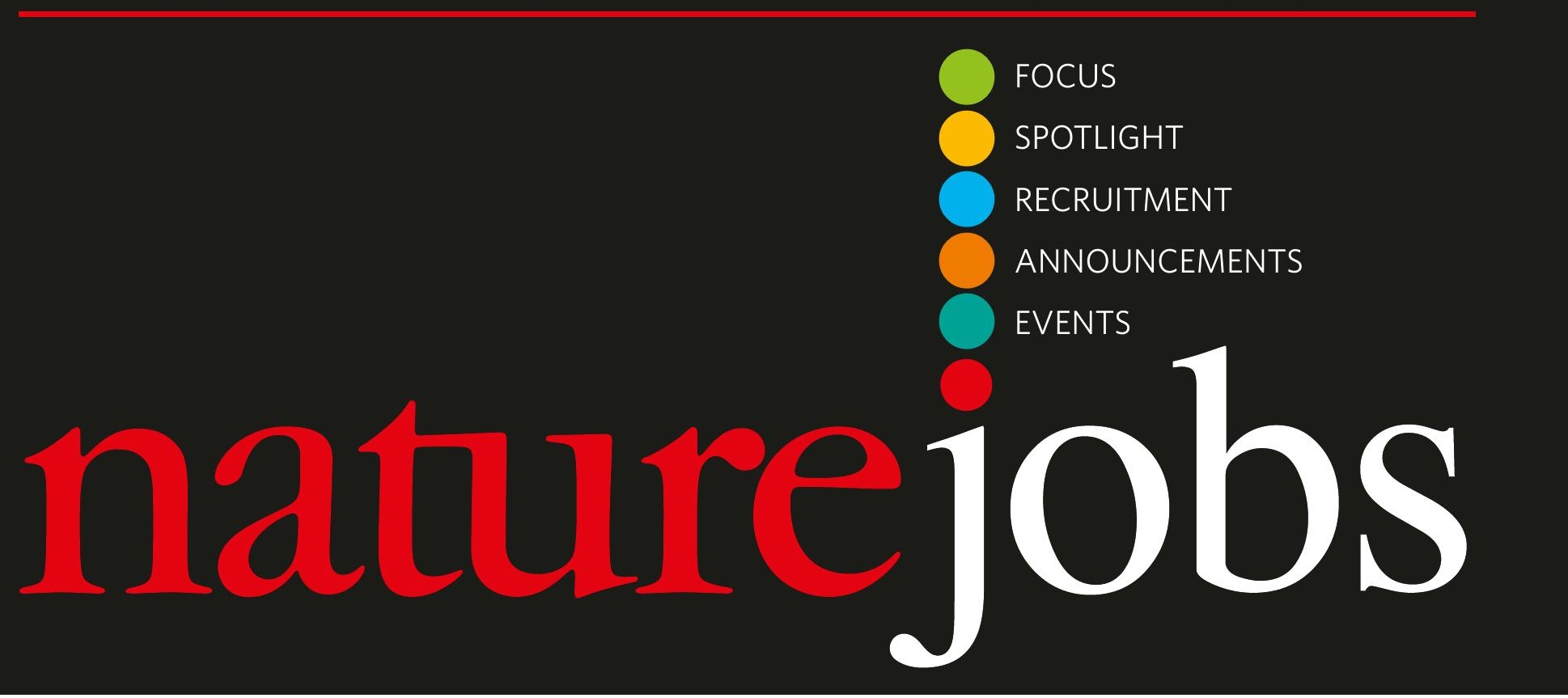

\section{Time for a change}

Tradition! That's the chorus and title for the opening song of Fiddler on the Roof, a musical set in a Jewish shtet/ in 1905 Russia. The play refers to the difficulties that dairyman Tevye has with accepting change. But if a recent letter to the Journal of the American Medical Association (JAMA)is to be believed, the play's themes also resonate with graduate medical education (K. M. Ludmerer and M. M. E. Johns J. Am. Med. Assoc. 294, 1083-1087; 2005).

The letter says that graduate medical education has failed to live up to its potential partly because of a "traditional subordination of education to service". But this sentiment broadly applies to all scientific education. In medicine, it means medical residents end up working 24-hour-plus shifts with little educational support. For scientific graduate students and postdocs, it means periods of training when their progress is beholden to principal investigators, who sometimes prolong the process to get more publications out of the young scientists they are supposedly mentoring.

Both the JAMA letter and this week's Recruiters \& Academia (see page 448), offer some alternatives to these traditions. The JAMA item suggests limiting the number of hours residents spend with patients, relieving residents of non-educational tasks, improving the educational content of training, and providing a support system to ease emotional stress. The Naturejobs item proposes taking some emphasis off publication record and rewarding other aspects of scientific work.

These changes could make science and medicine more attractive as career options. And they could make the professional development for both MDs and PhDs more productive - especially if it means they are treated as trainees, rather than workhorses. Ideally, better science and medicine would result. In Fiddler, Tevye eventually accepts change. Perhaps the scientific and medical establishment should as well.

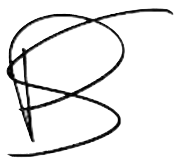

\section{Paul Smaglik, Naturejobs editor}

CONTACTS

Publisher: Ben Crowe

Editor: Paul Smaglik

Marketing Manager: David Bowen

US Head Office, New York

345 Park Avenue South, 10th Floor,

New York, NY 10010-1707

Tel: +1 8009897718

Fax: +18009897103

e-mail: naturejobs@natureny.com

US Sales Manager/Corporations: Peter Bless

Classified Sales Representatives

Tel: +18009897718
New York/Pennsylvania/

Latin America: Kelly Roman

Midwest USA/Maryland/

NIH: Wade Tucker

East USA/Canada:

Janine Taormina

San Francisco Office

Classified Sales Representative:

Michaela Bjorkman

West USA/West Corp. Canada

225 Bush Street, Suite 1453

San Francisco, CA 94104

Tel: +14157813803

Fax: +1 4157813805

e-mail:m.bjorkman@naturesf.com
European Head Office, London

The Macmillan Building,

4 Crinan Street,

London N19XW, UK

Tel: +44 (0) 2078434961

Fax: +44 (0) 2078434996

e-mail: naturejobs@nature.com

Naturejobs Sales Director: Nevin Bayoumi (4978) European Sales Manager: Andy Douglas (4975)

Advertising Production Manager: Billie Franklin To send materials use London address above. Tel: +44 (0) 2078434814

Fax: +44 (0) 2078434996

e-mail: naturejobs@nature.com
Naturejobs web development: Tom Hancock Naturejobs online production: Niamh Shields

European Satellite Office

Patrick Phelan

e-mail:p.phelan@nature.com

Japan Head Office, Tokyo

Chiyoda Building,

2-37 Ichigayatamachi,

Shinjuku-ku,

Tokyo $162-0843$

Tel: +81332678751

Fax: +81332678746

Asia-Pacific Sales Director: Rinoko Asami

e-mail: r.asami@naturejpn.com 